\title{
In Situ Infrared Spectroscopy as a Tool for Monitoring Molecular Catalyst for Hydroformylation in Continuous Processes
}

\author{
J. M. Dreimann, ${ }^{\dagger}$ E. Kohls, ${ }^{\ddagger}$ H. F. W. Warmeling, ${ }^{\dagger}$ M. Stein, ${ }^{\ddagger}$ L. F. Guo, ${ }^{\S}$ M. Garland, ${ }^{\S}$ T. N. Dinh, ${ }^{\S}$ \\ and A. J. Vorholt*,l® \\ $\dagger$ Laboratory of Industrial Chemistry, Department of Biochemical and Chemical Engineering, TU Dortmund, Emil-Figge-Straße 66, \\ 44227 Dortmund, Germany \\ ${ }^{\ddagger}$ Molecular Simulations and Design Group, Max Planck Institute for Dynamics of Complex Technical Systems, Sandtorstrasse 1, \\ 39106 Magdeburg, Germany \\ ${ }^{\S}$ Institute of Chemical and Engineering Sciences (ICES), 1 Pesek Road, Jurong Island 627833, Singapore \\ "Max-Planck-Institute for Chemical Energy Conversion, Stiftstraße 34-36, 45740 Mülheim, Germany
}

\section{Supporting Information}

ABSTRACT: Non-invasive in situ monitoring of catalyzed chemical reactions can show and probe the stability of the catalyst and ensure a high yield of the desired chemical processes. Infrared in situ measurement techniques in attenuated total reflection (ATR) and transmission mode were used to assess the feasibility of these methods and ultimately compare their ability to monitor and detect active or degrading catalyst species. Four different process configurations were used, namely (i) a stirred tank reactor equipped with ATR-IR; (ii) a continuously operated miniplant with ATR-IR; (iii) a continuously operated miniplant with transmission-IR; (iv) a stirred tank reactor equipped with transmission-IR. The established
Active catalyst
in process
Deactivated catalyst
during process

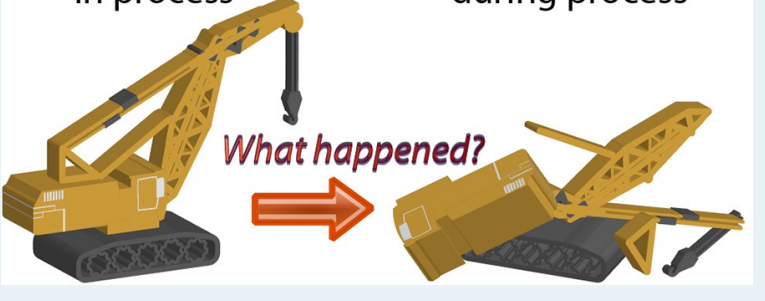
hydroformylation of a long-chain olefin catalyzed by a rhodium-phosphite catalyst was taken as a representative reaction. The potential for process monitoring in molecular catalysis was evaluated. Advanced chemometric analyses by Band Target Entropy Minimization (BTEM) were performed following spectral monitoring to obtain pure component spectra estimates as well as relative time-dependent concentration profiles. In general, this study showed that infrared measurements in transmission mode are able to detect active catalytic species and can follow deactivation phenomena in batch reactions and continuously operated miniplants. Apart from the substrates and products, a number of catalytic intermediates appear to be in equilibrium exchange at reaction conditions and hence the deconvolution of multispecies spectra exhibits superimpositions of these species. Quantum chemical calculations support the structural identification of measured vibrational spectra. This comparative study of ATR versus transmission and batch experiment versus continuously operated miniplant shows that transmission IR is capable of getting in-depth spectroscopic data that can be deconvoluted by BTEM. A distinct dosing strategy is important to get meaningful data on the molecular catalyst under process conditions. This study gives a unique perspective on in situ spectroscopic infrared investigations in molecular catalysis and future process control.

KEYWORDS: in situ spectroscopy, chemometrics, homogeneous catalysis, hydroformylation, infrared spectroscopy, miniplant

\section{INTRODUCTION}

In order to bring catalyzed reactions from the laboratory into the plant, the stability and the reactivation of the catalyst play a key role in reliability and cost of the process. This is especially true for molecular catalysts that need to be separated from the products by a physical barrier like distillation, multiphase systems, membranes etc. In this regard the topic of the utilization of in-line analytical tools for the real-time observation of chemical processes plays a key role to elucidate the deactivation of molecular catalysts. ${ }^{1}$ On-line or in situ spectroscopic measurements are often implemented to gain an insight into reaction kinetics and catalytic mechanisms. ${ }^{2-7}$ These techniques are also capable of providing a real-time insight into continuously operating processes with respect to conversions, yields and catalyst species, which is still rarely reported. These understandings are a key technology for stable and efficient process concepts. ${ }^{8}$

There are several ways to conduct in situ measurements. Very basic information is gained from simple bulk measurement parameters like density, conductivity etc. Information regarding the properties of products and substrates in the mixture can be gained from chromatographic techniques such as high-pressure liquid chromatography or gas chromatography. These techniques have an intrinsic time lapse between

Received: December 27, 2018

Revised: April 1, 2019

Published: April 1, 2019 

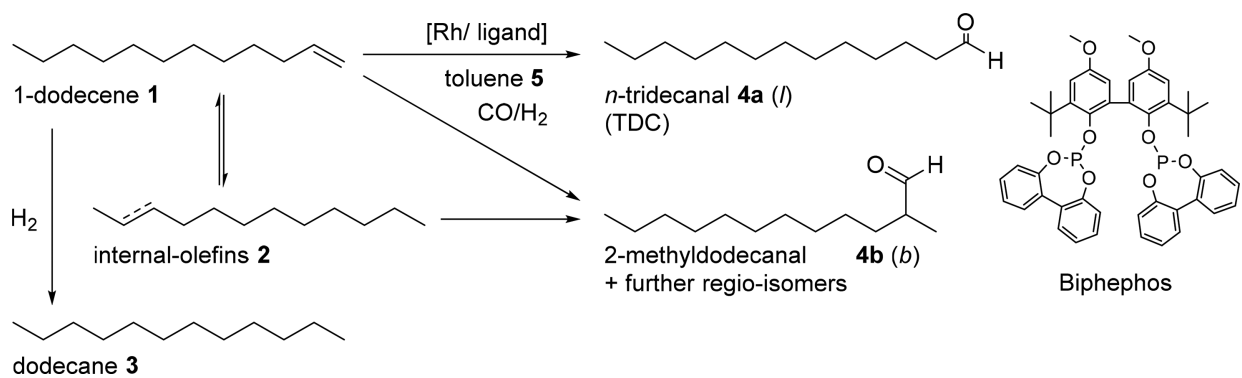

dodecane 3

Figure 1. Reaction scheme of the hydroformylation of 1-dodecene with syngas using $\mathrm{Rh}(\mathrm{I})$ biphephos as a catalyst and the most prominent side reactions.

Table 1. Overview of the Four Experimental Configurations in This Study

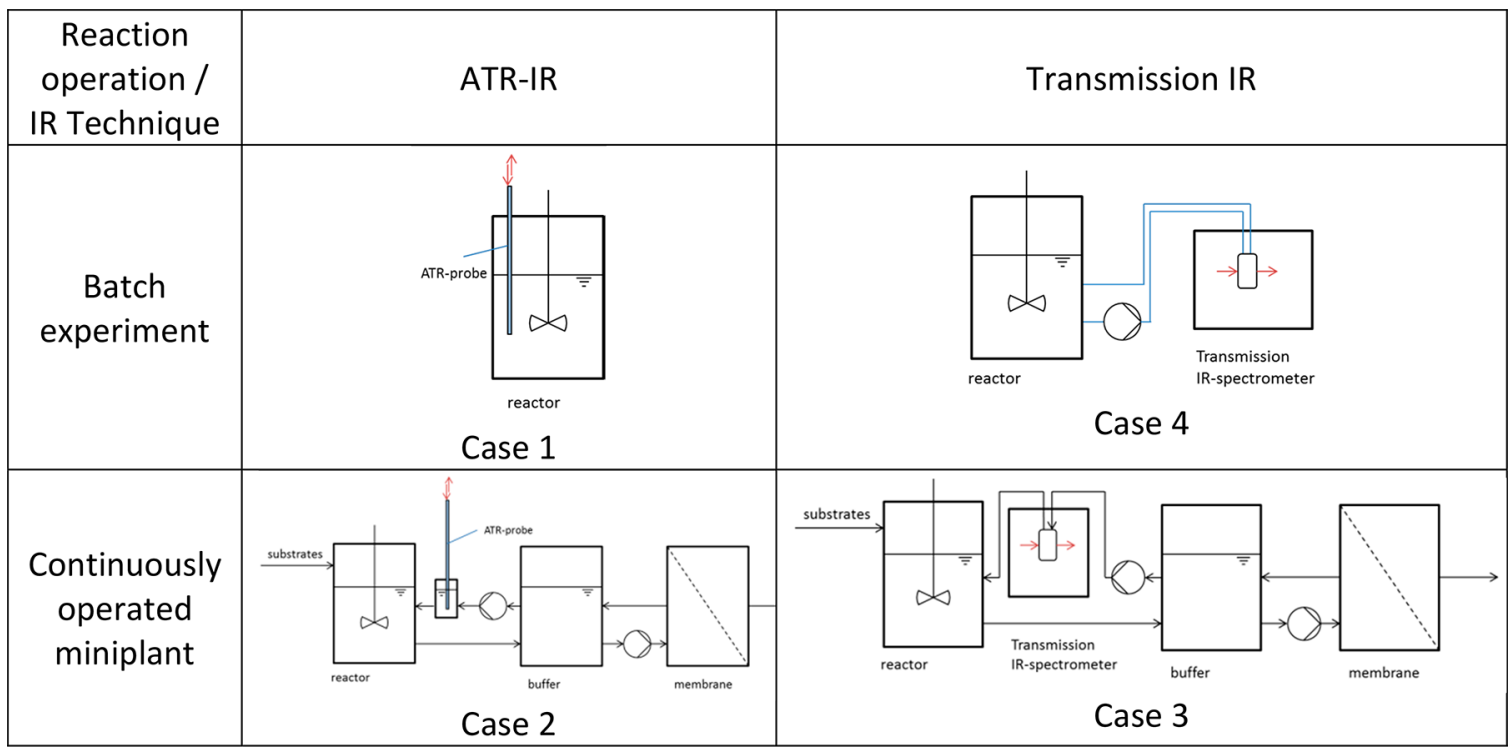

the time of sampling and the time the information is available and perturb the experimental setup by pulling samples. Noninvasive and real-time analytical tools with a high information density include spectroscopic measurements such as nuclear magnetic resonance, Raman, UV-vis and IR-spectroscopy., 9

The detailed information obtained by IR-transmission measurements has frequently been used to gain insights into the mechanisms of molecular-catalyzed reactions. ${ }^{2,5}$ Organometallic species such as metal carbonyl or metal hydride complexes can be identified with this sensitive technique. ${ }^{48}$ Depending on the catalyst properties, other suitable techniques for this purpose besides IR are NMR or Raman spectroscopy. Furthermore, the Lambert-Beer's law can be applied in the linear region of the detector's response to quantify concentrations in the sample solution. Two different measurement modes, namely attenuated total reflection (ATR) or transmission, are used for liquids.

The postprocessing of spectroscopic data has become an important tool over the past decade to gain more insights from complex spectral data that have been acquired over time. One method is Band Target Entropy Minimization (BTEM), ${ }^{11}$ an algorithm applied to big data sets to untangle multicomponent spectra and to obtain pure component spectra. ${ }^{4}$ This approach demonstrated its unique potential in several detailed mechanistic elucidations, e.g. the simplest mononuclear $\mathrm{Rh}$ carbonyl-hydride species was first identified using this tool. ${ }^{12}$ To the best of our knowledge, an infrared spectroscopic investigation on a process level with a BTEM postprocessing has not yet been described. ${ }^{13}$

In this work, the infrared spectroscopic technique is used to gain insights into a continuously operating process. The majority of publications on in situ IR techniques in literature focus on investigations of mechanisms. ${ }^{14,15}$ The established hydroformylation reaction was thus chosen as an example reaction. ${ }^{16}$ Since this reaction yields more than 12 million tons of aldehydes from olefins and syngas every year, the optimization of reaction conditions and improvement of process performance are of high relevance. ${ }^{17}$ Precious rhodium catalysts are often combined with sophisticated ligands to achieve a high selectivity for the desired linear aldehydes. ${ }^{18}$ On a large industrial scale, hydroformylation is performed continuously with low molecular weight substrates. When it comes to processing long-chain olefins from sustainable resources, the main challenge is to separate the high-boiling products from the temperature-sensitive catalysts and from the substrates.

Over the past few years, hydroformylation miniplants for the conversion of 1-dodecene to tridecanal (Figure 1) using twophase techniques such as thermomorphic multicomponent solvent systems (TMS) or micellar systems have been described as a practical solution to the separation problem. ${ }^{19-23}$ In addition, new reactor setups and the membrane separation of rhodium catalysts were recently demonstrated. $^{24,25}$ 
Unfortunately, all of the aforementioned continuous processes suffer from deactivation phenomena or catalyst degradation on a longer time scale. ${ }^{19,22,26}$ Nevertheless, this situation can be overcome by feeding new catalyst to the process. The deactivation of homogeneous transition metal catalysts over a long period is frequently observed and some mechanisms of the degradation of ligands or metal complexes have been proposed. ${ }^{16,27,28}$ In order to achieve reliable and stable continuous processes based on molecular catalysis, the deactivation needs to be detected at an early stage under real operating conditions, so that new and optimized operating procedures can be developed and implemented. ${ }^{29,30}$

Therefore, the present contribution has four goals, including

(i) the in situ spectroscopic study of the hydroformylation reaction using a commercially available ATR probe

(ii) the in situ spectroscopic study of the same reaction using a customized, high-pressure transmission infrared cell ${ }^{31}$

(iii) the use of the BTEM algorithm to deconvolute and untangle each set of data

(iv) the comparison of the quality of the results from these two individual spectroscopic investigations (ATR and transmission)

The test reaction in the continuously operated miniplant was conducted in toluene with 1 -dodecene as the substrate, a catalyst system consisting of $\mathrm{Rh}(\mathrm{CO})_{2}(\mathrm{acac})$ as the catalyst precursor and biphephos as the ligand (see Figure 1). ${ }^{32}$ In previous homogeneous catalytic studies, BTEM has been used exclusively in small batch scale experiments. ${ }^{4-7}$ The current study provides the opportunity to extend the application of BTEM to experimental data from a continuously operated miniplant. The objective of such a study is to better characterize the speciation during the long-term experiment and the time-dependent behavior of these species. An emphasis will also be placed on implementing appropriate experimental designs consistent with both miniplant operations as well as the known prerequisites for successful signal processing with BTEM. ${ }^{6}$

The use of quantum chemical calculations in the chemical industry has recently gained strong support due to the development of faster algorithms as well as computer hardware. $^{33,34}$

Table 1 provides an overview of the experiments conducted in this study. The first experiment was performed in batch mode and monitored by an ATR-probe (case 1). An ATR probe was also used in a continuously operated miniplant (case 2 ). The ATR probe was then replaced by a transmission probe in a continuously operated miniplant (case 3). Finally, the batch experiment was conducted with a transmission IR probe instead of the ATR (case 4).

The spectral ranges of the ATR and transmission IR employed in our experiments were primarily determined by both the optical materials and the detectors that were used. ${ }^{35}$ In general, the ATR-IR suffers from a rather low signal intensity and low spectral resolution $\left(8 \mathrm{~cm}^{-1}\right)$. The diamond prism in the ATR has a self-absorption band of around 2000 $\mathrm{cm}^{-1}$, which limits the spectral range, particularly for the metal carbonyl stretches. In addition, there is a cutoff below 750 $\mathrm{cm}^{-1}$ due to the MCT detector (equipped with a $\mathrm{ZnSe}$ window).

In contrast, $\mathrm{CaF}_{2}$ windows employed in the transmission IR probe have a self-absorbance cutoff below $1000 \mathrm{~cm}^{-1}$. In addition, the $\mathrm{CaF}_{2}$ windows, with a ca. $100 \mu \mathrm{m}$ path length, provide a significantly higher signal intensity with a lower noise level than the diamond prism. The transmission measurements were carried out at a resolution of $2 \mathrm{~cm}^{-1}$.

The constraints in the wavenumber ranges are materialrelated (Figure 2). For instance, the ATR-IR is also available

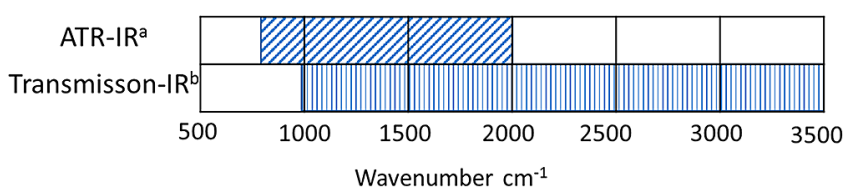

Figure 2. Different wavenumber ranges of the IR techniques used; ${ }^{a}$ React IR 15 Mettler Toledo with a diamond probe; ${ }^{b}$ Vertex70 Bruker with $\mathrm{CaF}_{2}$ cell windows.

with a silicon optic element that shows no self-absorption around $2000 \mathrm{~cm}^{-1}$. Also, the $\mathrm{CaF}_{2}$ windows can be substituted by diamond windows, which are for example more durable against solvents.

With respect to the implementation of the different probes, the ATR immersion probe is very easy to set up in both a continuous and batch operating mode. In contrast, the installation of a transmission IR cell in both a continuous and batch-operating mode requires a circulating liquid flow so that pump selection becomes a critical issue (Figure 3 ).

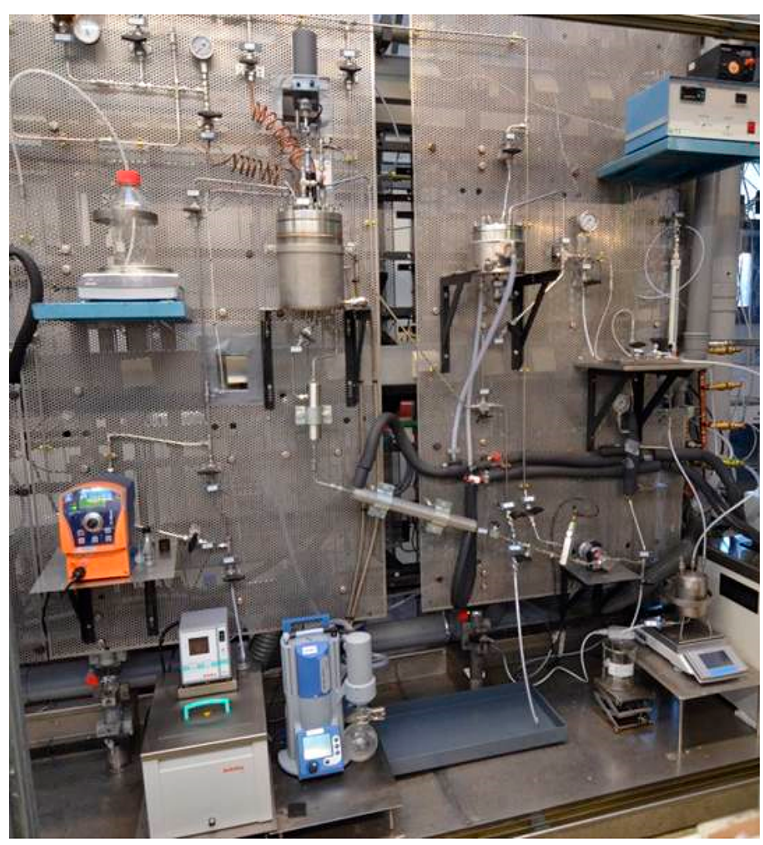

Figure 3. Picture of the miniplant.

\section{RESULTS}

All reactions in batch reactors and in the continuously operated miniplant were run with suitable experimental designs in order to facilitate spectral postprocessing with BTEM (see Section 2.2 for more details). As can be seen in Table 2 for a batch reaction, multiple perturbations were performed regarding substrate, catalyst precursor, ligand, solvent and partial pressure of $\mathrm{CO}$ and $\mathrm{H}_{2}$. At least $20 \mathrm{IR}$ spectra were taken after each change in operating conditions during the experimental run. This was done to ensure that a large number of spectra were available at each operating condition (Table 2). 
Table 2. Representative Sequence of Perturbations for the Batch Experiments in This Study

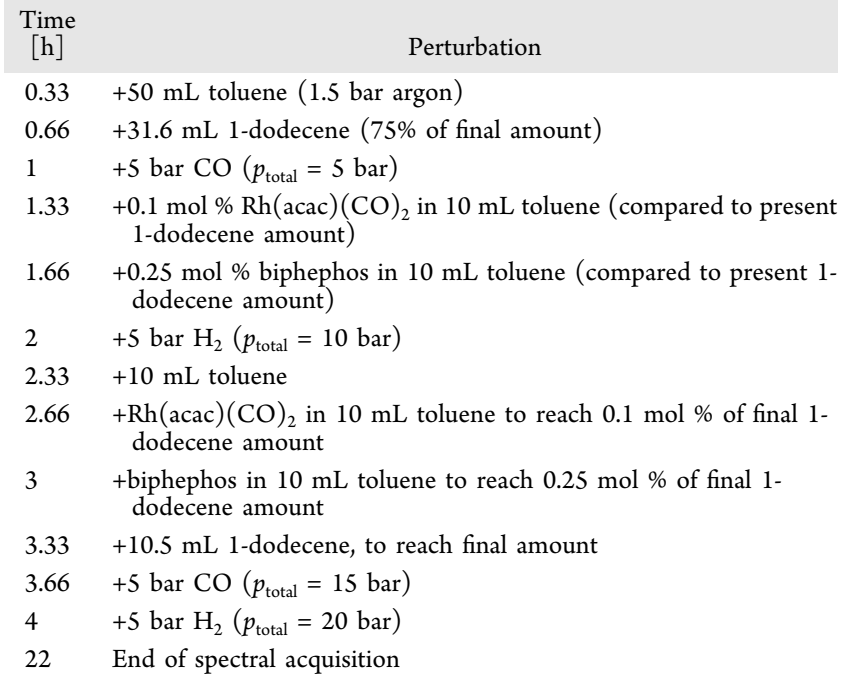

All IR-measurements were conducted at $60{ }^{\circ} \mathrm{C}$ in both batch and miniplant mode.

Case 1: Hydroformylation in a Batch Reactor Operated with an ATR-Infrared Probe. The first reaction was performed in a stainless-steel autoclave that was equipped with an ATR-IR probe and the dosing strategy was applied (see Table 1). Spectra were recorded in the course of the reaction. The raw spectral data obtained from this experiment are very complex. Many overlapping bands are present and some of these bands are clearly time-dependent (Figure 4).

This data set was then processed by BTEM in order to estimate the underlying pure component spectra and to provide the corresponding relative concentration profiles. From the acquired BTEM estimates also the perturbation experiments can be seen. First, the 1-dodecene was added to the pure toluene. Thereafter, the catalyst which was dissolved in toluene was added, which is shown by diluting the 1dodecene concentration in small steps in Figure 5. The addition of catalyst induced the isomerization to internal olefins after $1.5 \mathrm{~h}$. After $4 \mathrm{~h}$ the final concentrations and pressure were reached.
With a robust data set, the BTEM calculation usually gives accurate pure component spectral estimates. But in more difficult cases, the data can be colinear and some of the resulting "pure spectral estimates" will be superimpositions of spectra. ${ }^{36}$ The results from the analysis of the fingerprint region are presented in Figure 5. For example, the pure component spectral estimates for toluene (5) and the pure component spectrum for the substrate (spectrum 1) appear to be accurate. However, the spectral estimates for internal olefins (2) and aldehydes $(4 \mathbf{a} / \mathbf{4 b})$ are probably superimpositions of a number of isomers. These deconvoluted organic species spectra were consistent with the GC results. Moreover, an additional spectral estimate was recovered (spectrum 6a). An inspection of spectrum 6a suggests that it is probably the superimposition of a few species due to the very complex speciation of organometallics, the probable degradation of the ligand and the limitations of the experimental design and the low-resolution of the ATR instrument.

The deconvoluted spectrum (6a) cannot be unequivocally assigned to one of the organic compounds in this spectral range. In order to investigate the origin of these signals, density functional theory (DFT) calculations were performed for many different rhodium biphephos degradative species as well as the free ligand (Figure 6). Spectrum 7a originates from the hydrido-dicarbonyl-biphephos-rhodium precatalyst complex, and its spectral properties are shown in the range of interest, i.e. from 1100 to $1300 \mathrm{~cm}^{-1}$. According to the calculations, this is one of the most stable species in the reaction cycle and other research groups successfully identified or isolated similar bisphosphites as an important, or the most abundant species. ${ }^{37,38}$ The free ligand $(\mathbf{7 b})$ displays the same absorption bands at around 1160 and $1175 \mathrm{~cm}^{-1}$. The calculations clearly show that these vibrational absorptions arise from the stretching $\mathrm{C}-\mathrm{O}$ modes originating from the phosphite oxygens and aromatic carbons of the biphephos ligand coupled with aromatic $\mathrm{C}-\mathrm{H}$ in-plane bends. The $\mathrm{P}-\mathrm{O}$ phosphite stretches occur below $1000 \mathrm{~cm}^{-1}$ in the calculations. Hydrolysis of the phosphites occurs due to traces of water that result from aldol condensation of the aldehyde products. Although being less sensitive to oxidizing agents, bulky phosphite decomposition can be mediated by oxygen and radicals. To also include these possibilities, both hydrolyzed and oxidized ligands were also

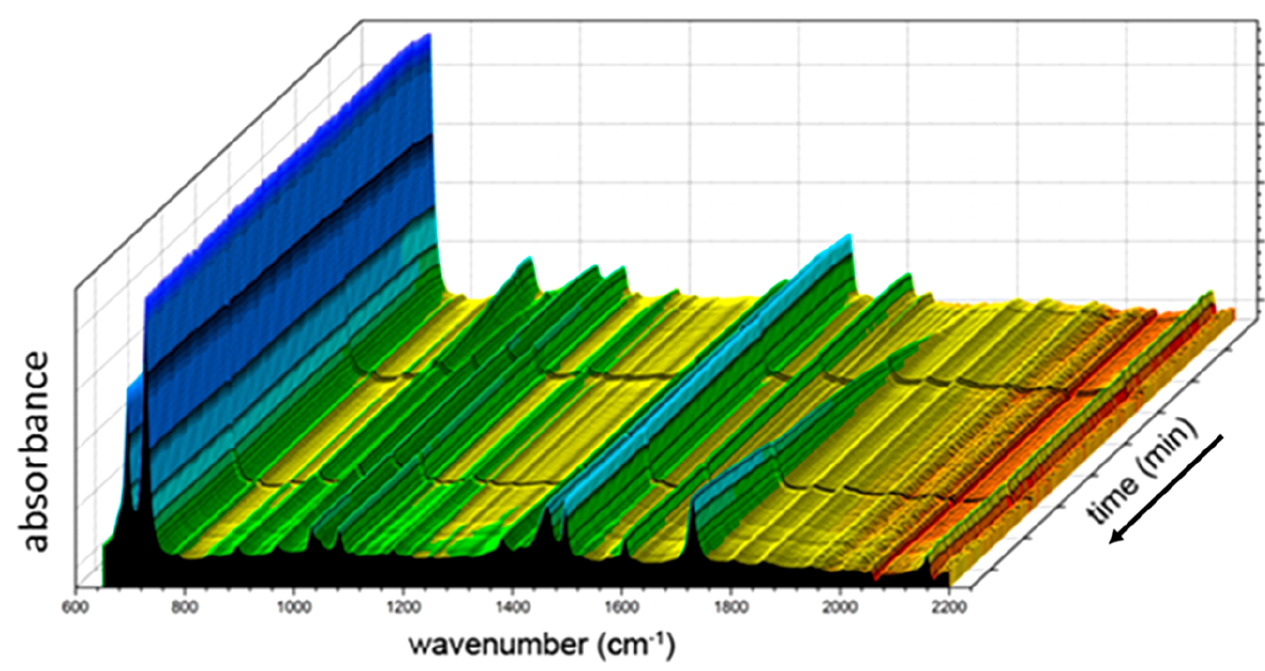

Figure 4. Unprocessed ATR-IR spectrum of the hydroformylation of 1-dodecene in toluene catalyzed by a rhodium biphephos complex. 

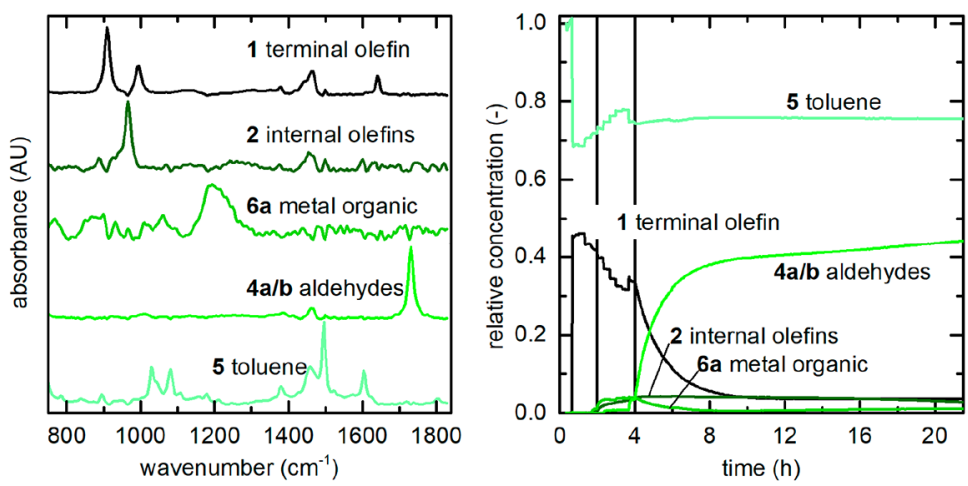

Figure 5. (left) BTEM spectral estimates from ATR-IR batch experiment at $60^{\circ} \mathrm{C}$ (case 1). (right) Corresponding relative concentration profiles.

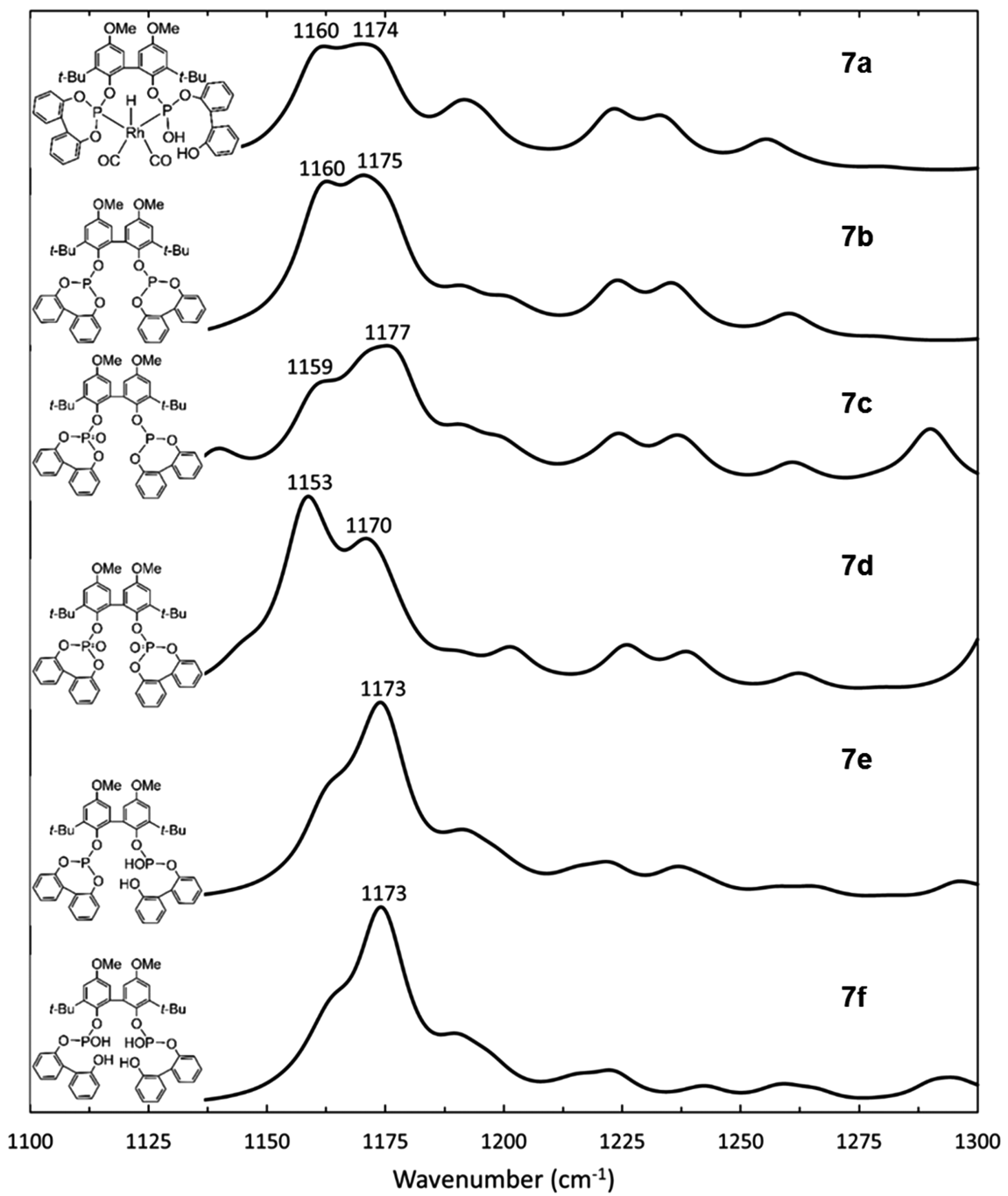

Figure 6. IR-spectra of the hydrido dicarbonyl Rh-complex, the original biphephos ligand and some oxidized and hydrolyzed ligand species obtained from DFT calculations.

tested by computational means. As Figure 6 shows, these degraded ligands show vibrations around $1160 \mathrm{~cm}^{-1}$, with a slight shift toward smaller values in the oxidized and higher values in the hydrolyzed species. However, the absorption around $1175 \mathrm{~cm}^{-1}$ remains almost unchanged. Because there is no significant change in this band upon complexation or hydrolysis and oxidation, it is hard to assign the measured vibration to a specific species. Additionally, there are more degradation pathways possible, like monophosphite ligand alkylations etc. ${ }^{29}$ By comparing the DFT and BTEM results, it is apparent that such an organometallic species can originate from the biphephos ligand, whose concentration declined over time.

Case 2: ATR-IR Measurements in a Continuously Operated Miniplant. In case 2, the ATR-IR probe was implemented in a continuously operated miniplant. This 


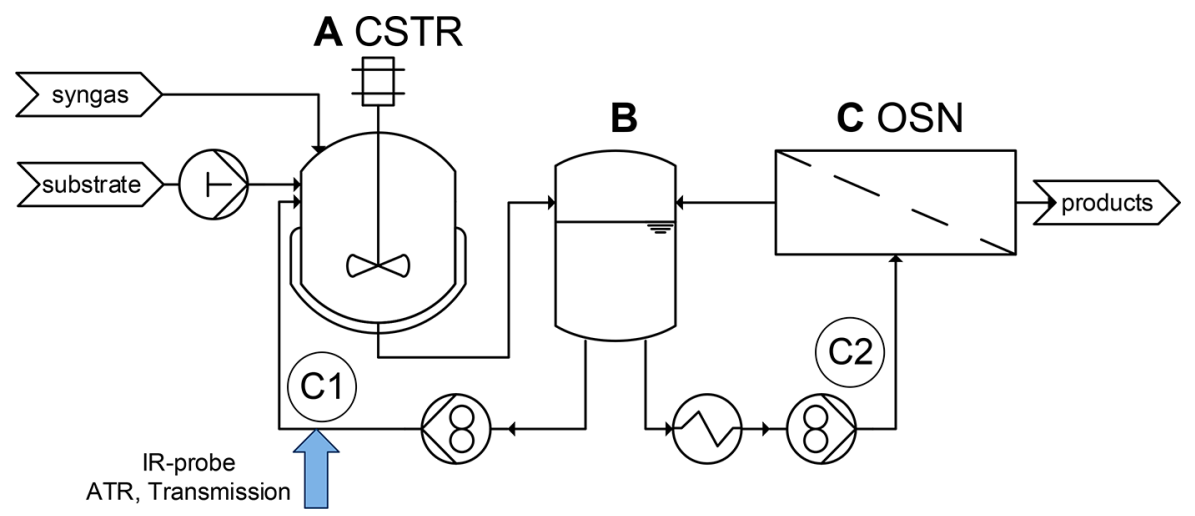

Figure 7. Continuously operated miniplant with the probe position indicated for both ATR (case 2) and transmission (case 3 ) in the recycling loop. A continuously operated stirred tank reactor, B hold up tank, C OSN unit, C1 Recycling stream to the reactor, C2 Recycling stream to the OSN unit.
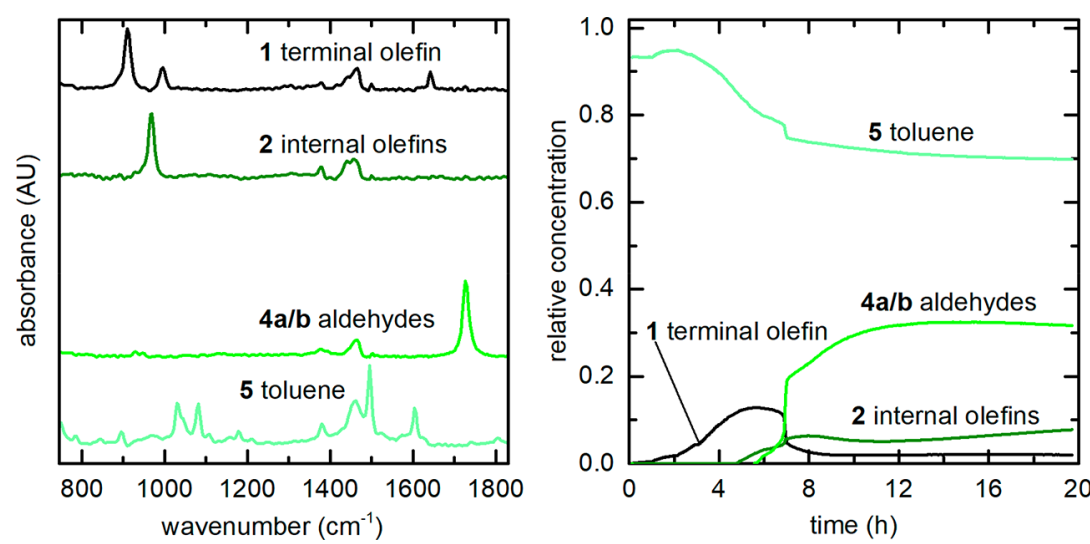

Figure 8. Results from the experiment with the ATR-IR in the membrane miniplant (case 2). (a) BTEM spectral estimates. (b) Corresponding relative concentration profiles.

miniplant was designed to retain homogeneous catalyst by organic nanofiltration. As previously reported, the miniplant consists of two separate loops with different flow rates. The loop from the reactor $\mathrm{A}$ into the holdup $\mathrm{B}$ and back to the reactor $\mathrm{A}$ is operated at $3.5 \mathrm{l} / \mathrm{h}(\mathrm{C} 1)$ while the loop from the holdup unit $\mathrm{B}$ to the membrane unit $\mathrm{C}$ and back to the holdup unit B is operated at a rate of up to $120 \mathrm{l} / \mathrm{h}$ (C2, Figure 7). A PDMS-membrane (GMT2) was employed. ${ }^{39}$ The position of the ATR-probe in the recycle stream to the reactor was chosen by considering a location in the miniplant with a relatively high catalyst concentration and a moderate flow rate.

During the course of this experiment, all of the reagents were dosed into the holdup unit. IR-data were acquired over $20 \mathrm{~h}$. The data was then processed by BTEM. The deconvoluted spectra and relative concentration profiles are shown in Figure 8.

As in case 1 , toluene (5), aldehydes $(4 \mathbf{a} / \mathbf{b})$, terminal alkene (1) and internal alkenes (2) could be observed. The relative concentration profiles were consistent with the GC data. In contrast to case 1 , no organometallic spectra could be reconstructed. The ATR-IR technique in this case is not sensitive enough to show catalyst complexes at a ppm level. Since dosing into the miniplant was carried out via the holdup tank, the corresponding signal of the rhodium species in the IR data is not intense. The newly introduced component is diluted in the membrane loop before it enters the recycle loop. This significantly decreases the signal intensity and therefore hinders the BTEM analysis.
Case 3: Transmission-IR Measurements in a Continuously Operated Miniplant. The finding that ATR-IR was not providing spectral data for organometallic species in the miniplant prompted the use of a flow-through cell in transmission mode. The cell is located at the same position as the ATR-probe in case 2. The process was operated over $48 \mathrm{~h}$ while IR-data were acquired. The raw data were analyzed by BTEM. Two wavenumber ranges, one higher range from 1750 to $2850 \mathrm{~cm}^{-1}$ and one lower range from 1100 to $1450 \mathrm{~cm}^{-1}$, were investigated independently since the alkene band at 1630 $\mathrm{cm}^{-1}$ and the aldehyde band at $1700 \mathrm{~cm}^{-1}$ exceed the signal intensity for the linear response regime interpretation. This means that it is not possible to analyze the aldehyde region by BTEM. The results of the BTEM analysis are shown in Figure 9 as the pure component spectra estimates and the corresponding relative concentration profiles.

The BTEM analysis in the higher range of wavenumbers $\left(1750-2850 \mathrm{~cm}^{-1}\right)$ provided pure component spectral estimates of the rhodium precursor (8), carbon monoxide (7) and the two aldehyde isomer products $(4 \mathbf{a} / \mathbf{b})$ which were not detectable in cases 1 and 2 where the ATR probe was used. The corresponding relative concentration profiles show that the rhodium complex is relatively stable over time. The BTEM analysis of the lower range of wavenumbers (1100-1450 $\mathrm{cm}^{-1}$ ) shows that the relative concentration of the linear aldehyde (4a) increased very rapidly at the initial time and the concentration of the branched aldehyde (4b) started to increase later (at ca. $20.5 \mathrm{~h}$ ) during the continuous experiment. 

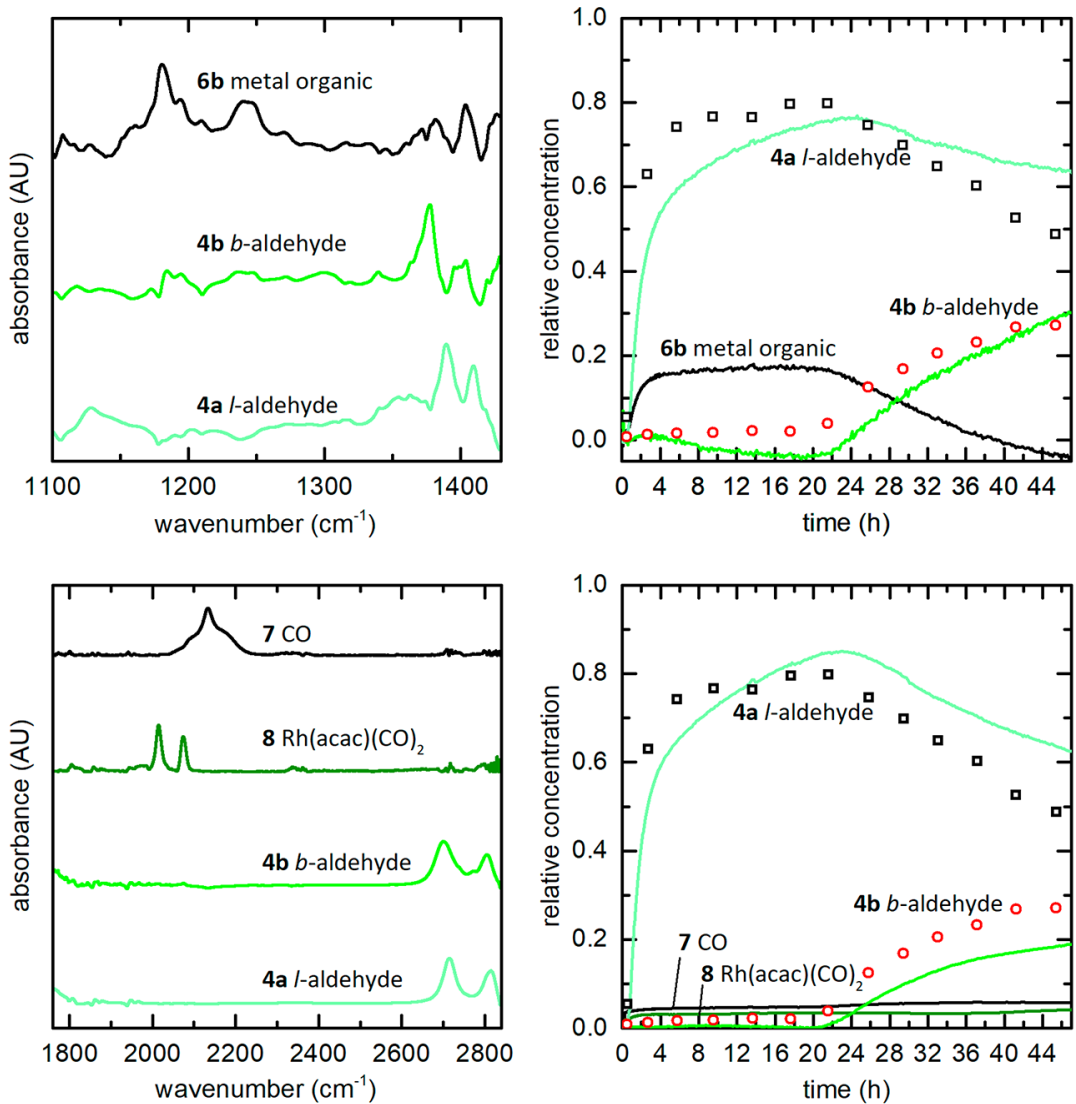

Figure 9. BTEM spectral estimates and relative concentration profiles associated with the flow-through transmission IR cell implemented in a continuously operated miniplant (case 3 ). The dotted lines represent the GC data.
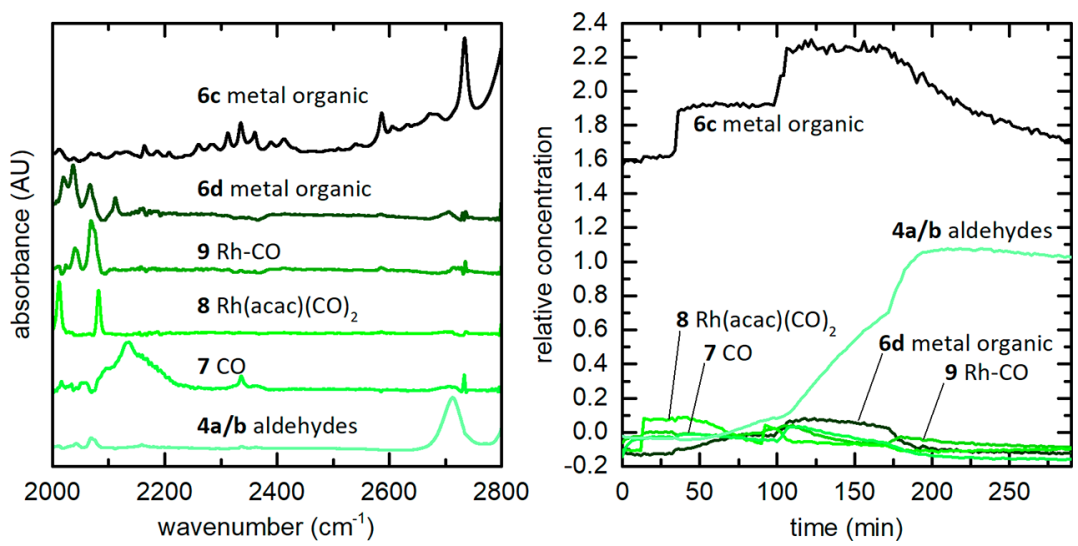

Figure 10. Batch experiment conducted at $60{ }^{\circ} \mathrm{C}$ (flow-through recycle on small-scale experiment performed on Bruker Vertex 70 in the Mid/FarIR region. BTEM analysis was performed within the range of $2000-2800 \mathrm{~cm}^{-1}$.

The assignment of the linear and branched aldehydes $4 \mathbf{a}$ and 4b was based on the similarity in the corresponding concentration profiles of these two spectra estimates compared to the concentration profiles obtained by the analysis of the higher wavenumber region. In addition, the assignments to the linear and branched aldehyde spectra are corroborated by the GC data (Figure 9, dotted data points). In fact, a yield of $80 \%$ of linear aldehydes was measured with only $2 \%$ of branched aldehydes during the first $20 \mathrm{~h}$. After $20 \mathrm{~h}$, the value of branched aldehydes rises to $30 \%$.

As discussed previously in case 1 , the spectral estimate of the metal complexes/ligand (6b) in the region $1100-1450 \mathrm{~cm}^{-1}$ is in fact a superimposition of more than one complex species.
The complex (6b) overlapping biphephos spectra estimates have a rather constant intensity until ca. $20.5 \mathrm{~h}$, and then the intensity rapidly declines. This suggests the degradation of the core biphephos structure of the rhodium catalytic species and hence the loss of selectivity in the hydroformylation starting at ca. 20.5 h. It is already known that biphephos is not inert ${ }^{22}$ so that this information may be important to control homogeneous catalyzed processes in the future.

Although the region below $1000 \mathrm{~cm}^{-1}$ could not be observed due to the $\mathrm{CaF}_{2}$ window cutoff, the continuous experiment with transmission FTIR spectroscopy (case 3) provided considerably more insights into the speciation and concentration profiles compared to the ATR experiments (case 1 and 

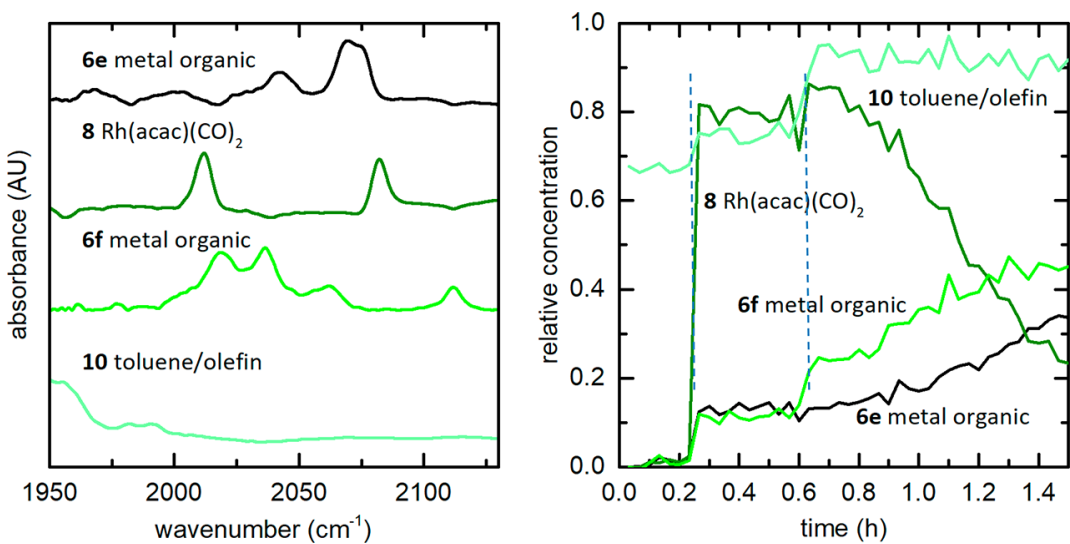

Figure 11. BTEM spectral estimates and relative concentration profiles associated with the organometallic species in case 4 in the $1950-2150$ wavenumber region.

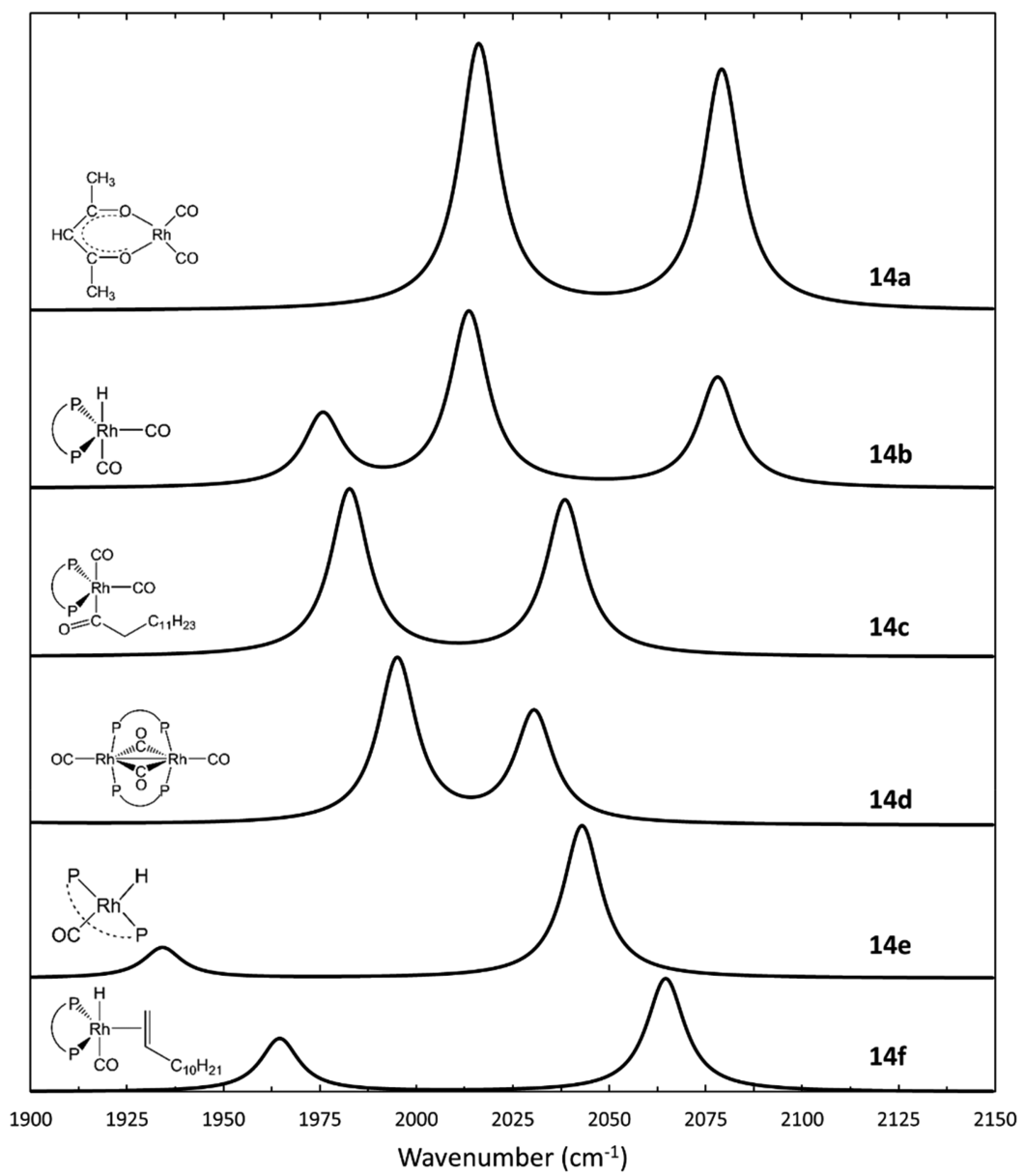

Figure 12. Calculated IR spectra of prominent organo-rhodium species present in the system.

2). This is especially true with regard to the observation of metal organics, which inherently appear at ppm concentration levels. The enhanced sensitivity of the transmission measurement reduces the accuracy of the high concentrated compounds like aldehydes or olefins. This can be seen by the deviation of the GC and IR data. The trend of both methods is the same while the IR becomes more inaccurate with higher concentrations.

Case 4: Transmission-IR Measurements in a Batch Reactor. In the ATR-IR batch experiment (case 1) and the transmission IR experiment in a continuously operated miniplant (case 3), it was possible to observe some organometallic species $(6 \mathbf{6} / \mathbf{b})$. In an attempt to better disentangle the spectral estimates of overlapping organometallic species observed in case 1 and case 3, a transmission IR measurement in a batch reactor was performed.

As in case 1 , the same reaction conditions and perturbation strategy were applied. IR-measurement was performed over 5 $h$, and the data were processed by BTEM to obtain the pure component spectral estimates and the corresponding concentration profiles. These results are shown in Figure 10. 
A preliminary BTEM analysis was performed in the higher wavenumber region $\left(2000-2800 \mathrm{~cm}^{-1}\right)$. The organic species such as the aldehyde product $(\mathbf{4 a} / \mathbf{b})$ and $\mathrm{CO}(7)$ can be assigned. Since only traces of branched aldehydes were synthesized, the corresponding spectral estimate was not obtained from this experiment. It is worth noting that three new organometallic species could be observed (6c, 6d, 9) together with the known rhodium precursor (8) in this experiment. The better signal-to-noise ratio of the transmission IR-data provided the possibility of obtaining more single component spectra, and therefore a more detailed insight into the catalytic mechanism. The main difference between case 4 and case 3 was in the experimental design, specifically the dosing strategy. In the batch setup, the dosing returns a quasiimmediate response in the IR-data, whereas the response was delayed in the continuously operated miniplant system due to its higher volume.

A BTEM analysis was performed once again with an emphasis on the $1950-2150 \mathrm{~cm}^{-1}$ wavenumber region to allow a closer examination of the time-dependent relationship between the rhodium precursor (8) and the three newly deconvoluted organometallic species $(\mathbf{6 c}, \mathbf{6 d}, \mathbf{9})$. The new sets of pure component spectra and corresponding relative concentration profiles are shown in Figure 11.

Within the wavenumber region selected for the current analysis, i.e from 1950 to $2150 \mathrm{~cm}^{-1}$, the signal contribution of the olefin is almost insignificant. Furthermore, only a small amount of olefin was converted to the aldehyde product in the course of the reaction, especially during the initial hours, so that the initial mixture spectrum of toluene solvent and olefin substrate was used as the fourth component for the purpose of data fitting.

Using this four-component model, we obtained a new set of time-dependent concentration profiles. These are shown in Figure 12: (6e) the first new organometallic species; $(8)$ the $\mathrm{Rh}(\mathrm{acac})(\mathrm{CO})_{2}$ precursor; (6f) the second new organometallic species; (10) toluene solvent and olefin substrate mixture. In the more precise examination of the narrower wavenumber region, the three metal complexes $(6 \mathrm{c}, 6 \mathrm{~d}, 9)$ turn out to be just two.

In Figure 12, the precursor $\mathrm{Rh}(\mathrm{acac})(\mathrm{CO})_{2}$ had a relative concentration of around 0 for roughly $12 \mathrm{~min}$. The precursor $\mathrm{Rh}(\mathrm{acac})(\mathrm{CO})_{2}$ was then injected at this point in time. The relative intensity rapidly increased and remained constant for ca. 32 min, when biphephos ligand was injected and $\mathrm{H}_{2}$ was added. There was a slow decline in the relative concentration of the precursor for the rest of the reaction period. Upon injection of the precursor $\mathrm{Rh}(\mathrm{acac})(\mathrm{CO})_{2}$, and in the presence of both $\mathrm{CO}$ and alkene substrate two new pure component spectral estimates appeared and the relative concentration remained constant until the injection of biphephos ligand $(t=$ $12 \mathrm{~min})$ and the addition of $\mathrm{H}_{2}(t=32 \mathrm{~min})$. The relative intensity of this newly formed organometallic species increased steadily for the remainder of the reaction period.

It becomes clear from the concentration profile that the precursor (8) is consumed to form the two organometallic species $(6 \mathbf{6} / \mathbf{f})$. DFT calculations were performed to help elucidate the newly deconvoluted spectra (Figure 12).

The free ligand biphephos (BPP) does not absorb in this region, so that a band in this spectral range must originate from a rhodium complex. This is most probably from a carbonylcontaining complex, since the bands due to $\mathrm{CO}$ absorption occur at around $2000 \mathrm{~cm}^{-1}$ and are well separated from other vibrations in the spectrum. The first spectrum in the top of Figure 12 (spectrum 14a) is the calculated spectrum of the precursor $\mathrm{Rh}(\mathrm{acac})(\mathrm{CO})_{2}$, which shows an excellent agreement with the experimental spectrum presented in Figure 11 with respect to the positioning of the bands, their relative intensity and spacing. In order to identify the other two spectra in Figure 11, theoretical spectra of several Rh-carbonyl complexes were computed. Together with the precursor, $\mathrm{HRh}(\mathrm{BPP})(\mathrm{CO})_{2}$ (spectrum 14b) and Rh(BPP)$(\mathrm{CO})_{2}$ (tridecanoyl) (spectrum $14 \mathrm{c}$ ) are two of the most stable species in the catalytic reaction network according to our calculations. Similar results were obtained in other hydroformylation studies. ${ }^{40}$ Nevertheless, neither of the deconvoluted experimental spectra matches the positioning of the calculated bands of these two complexes. Dimeric complexes are often mentioned in literature as a possible pathway for catalyst loss. ${ }^{41} \mathrm{~A}$ theoretically predicted spectrum of a dimeric Rh-complex containing two bridging and two terminal carbonyl groups is also presented in Figure 12 (spectrum 14d). In the depicted region from 1900 to $2150 \mathrm{~cm}^{-1}$ the dimeric complex only exhibits two absorptions because the two bridging $\mathrm{CO}$ absorptions occur around $1800 \mathrm{~cm}^{-1}$ and are not presented here. The fifth and the sixth spectrum in Figure 12 originate from hydrido monocarbonyl complexes (14e and 14f), assuming that a tentative complex contains hydrogen and $\mathrm{CO}$ in axial positions and biphephos in equatorial-equatorial (e,e) position. The computed $\mathrm{CO}$ absorption of this unsaturated complex appears at $2043 \mathrm{~cm}^{-1}$. It is not very likely that an experimental spectrum would originate from an unsaturated 16 electron species, but this has been included here to prove the hypothesis of the axial arrangement of $\mathrm{H}$ and $\mathrm{CO}$ as well as the e,e arrangement of the biphephos ligand. The band shifts to higher frequencies by around $20 \mathrm{~cm}^{-1}$ upon saturation of the complex with the substrate. The respective band at $2065 \mathrm{~cm}^{-1}$ offers a potential interpretation of the experimental spectrum $(6 e)$.

Indeed, all the 18 electron mononuclear organo-rhodium species considered in this system have $3 \mathrm{CO}$ vibrations or less, and the two remaining BTEM spectral estimates have at least 4 bands each. This suggests that the 2 remaining "pure component" spectral estimates in Figure 11 are very likely due to the superimpositions of 2 or more species. Finally, we note that no bridging carbonyls (ca. $1800 \mathrm{~cm}^{-1}$ ) remain in the BTEM spectral estimates, therefore ruling out the presence of significant amount of dinuclear rhodium complex.

These findings show that under the chosen conditions, metal catalyst complexes can be observed. More data in a wider spectral range have to be recorded to obtain better deconvolution results.

\section{CONCLUSION}

In the context of this paper, two IR-techniques have been tested in a batch reactor setup and in a continuously operated miniplant under industrially relevant conditions. Time-dependent IR data were collected and processed by BTEM. Both ATR-IR and transmission-IR were able to track the organic species such as substrates, products and side products. Linear and branched aldehydes as well as terminal and internal alkenes could be observed depending on the experimental setup such as wavenumber range of the technique restricted by window material or instrumental setup. BTEM estimates and GC results were consistent in terms of concentration profiles for all organic compounds. 
Table 3. Outcome of Spectroscopic Data after BTEM Treatment

\begin{tabular}{|c|c|c|c|c|}
\hline Detection of & ATR (autoclave batch) case 1 & $\begin{array}{c}\text { ATR } \\
\text { (miniplant) } \\
\text { case } 2\end{array}$ & $\begin{array}{c}\text { Transmission (miniplant) } \\
\text { case } 3\end{array}$ & Transmission (autoclave batch) case 4 \\
\hline Substrate (olefin) & $\sqrt{ }$ & $\sqrt{ }$ & $\sqrt{ }$ & $\sqrt{ }$ \\
\hline Products (aldehyde) & $\sqrt{ }$ & $\sqrt{ }$ & $\sqrt{ }$ & $\sqrt{ }$ \\
\hline $\begin{array}{l}\text { Side products (olefin isomers, } \\
\text { branched aldehydes) }\end{array}$ & $\begin{array}{l}\sqrt{ } \text { Terminal and internal } \\
\text { alkenes }\end{array}$ & $\sqrt{ }$ & $\begin{array}{l}\sqrt{ } \text { Branched and linear } \\
\text { aldehydes }\end{array}$ & $\sqrt{ }$ \\
\hline Organometallics & $\begin{array}{l}\text { Mixture of } \mathrm{Rh} / \text { biphephos } \\
\text { complexes assigned }\end{array}$ & Not observed & $\begin{array}{l}\text { Mixture of } \mathrm{Rh} / \text { biphephos } \\
\text { complexes assigned }\end{array}$ & $\begin{array}{l}\text { More precise mixture of } \mathrm{Rh} / \text { biphephos } \\
\text { complexes assigned }\end{array}$ \\
\hline
\end{tabular}

In the continuously operated miniplant, a decrease of a single spectrum signal at $1150 \mathrm{~cm}^{-1}$ was observed by ATR and transmission IR. The decay of this signal corresponds to the loss of selectivity to branched aldehyde products of the catalytic system in the miniplant. This indicates that this band can be used in further experiments to monitor the decomposition of the Rh-ligand complexes. Furthermore, this finding can be used in future to control the process directly by monitoring this catalyst vibrational feature.

DFT was used to reconcile the BTEM spectral estimates and assign organo-rhodium species to the BTEM spectra. More accurate data on the organo-metallic species can be obtained if a more controllable reactor setup with a precise dosing is combined with transmission-IR. In this case, rhodium complexes can also be followed and characterized by DFT calculations. Table 3 offers an overview of the four different cases.

In conclusion, ATR-IR has the benefit of an easy setup, but the limited wavenumber range combined with the low intensity of the signal make it difficult to obtain information on organometallic compounds. This technique is suitable to track all organic chemicals in the process.

Transmission-IR is more difficult to implement because of the need for a distinct flow. The wavenumber range is larger and the data acquisition therefore of a higher information quality. The intensity of the signals enables a spectral detection of organometallic intermediates.

In both techniques, a suitable dosing strategy to start the reaction is crucial for the postprocessing of the data by BTEM. The more precise the dosing, the better the quality of the data. This is an intrinsic hurdle for continuously operated systems since the increased holdup and the position of dosing is more indirect compared to a batch experiment.

In the future, the BTEM algorithm has to be developed into a code that can be fed continuously with new data in order to make the data more accurate and to detect and identify degradation of the catalyst species on the fly.

In the future, a combination of transmission-IR with UV-vis or Raman techniques in the same miniplant may be able to solve the challenges that have arisen and provide better data for both organic and organometallic compounds. The decomposition of catalyst complexes in the process can be followed in the future in real time with this setup. This has a potential impact on controlling stability in the homogeneously catalyzed processes and the design of new ligand classes toward an increased stability.

\section{EXPERIMENTAL SECTION}

Band Targeted Entropy Minimization (BTEM). Band Target Entropy Minimization (BTEM) is a "blind source separation" program that generates the underlying pure component spectra present in a spectroscopic data set without the use of any a priori information. The usual input for the BTEM algorithm is simply a large set (hundreds or thousands) of spectra taken from a homogeneous catalytic reaction. The chemical constituents introduced into the reaction are of no importance to the algorithm. BTEM searches for the simplest underlying patterns in the data set, where the term "simplest" has a strictly mathematical meaning in the sense of minimizing signal entropy. If an adequate experimental design with multiple perturbations is used (see Table 2), then the simple patterns normally correspond to very accurate estimates of the pure component spectra. With an adequate vibrational spectroscopic quality and suitably robust data sets, pure component spectra for components at the $1 \mathrm{ppm}$ level can be reconstructed, often with a 25:1 signal-to-noise ratio. The BTEM algorithm analyzes the data set by recovering one pure component spectrum at a time until all of the residual information is exhausted. Further details on the mathematical constructs of BTEM and its uses in homogeneous catalysis can be found in the original journal papers. ${ }^{6,11}$

Computation of IR Spectra. DFT calculations were performed using Turbomole $\mathrm{v} 6 .^{42}$ The BP86 $6^{43,44}$ functional was used by employing the RI approximation. ${ }^{45} \mathrm{~A}$ triple- $\zeta$ basis set with polarization functions $\left(\operatorname{def} 2-\mathrm{TZVP}^{46}\right)$ was used for all atoms. All of the investigated candidate structures were identified as being minima on the potential energy surface due to the absence of any imaginary frequency. A scaling factor of 1.004 was used for the low frequencies, ${ }^{47}$ whereas a scaling factor of 1 was used for the carbonyl region. ${ }^{48}$ The BP86 functional was shown to provide more accurate $\mathrm{Rh}(\mathrm{I})$-carbonyl vibrational frequencies than the hybrid B3LYP functional for a series of 45 compounds and allowed the assignment of experimental spectral features. ${ }^{48}$

Batch Autoclave Experiments. The experimental equipment used in case 1 (ATR-batch autoclave) consisted of a 300 $\mathrm{mL}$ pressure autoclave (Parr Instruments) with overhead stirring and electrical heating. A Mettler Toledo ReactIR 15 with an ATR-IR probe with a diamond optical window was used.

Prior to filling the reactor, it was evacuated and then flushed with argon (3 times). After the reactor had been heated up to the required reaction temperature, the reaction mixture was introduced into the reactor and sampled as stated in Table 2. All steps were carried out using standard Schlenk technique. In order to overcome the increasing pressure inside the reactor, all of the components were introduced into the reactor via a pressure sluice.

Reaction conditions: $m_{\text {total }}=50 \mathrm{~g}, w_{1 \text {-dodecene }}=0.25(223$ $\mathrm{mmol}), w_{\text {toluene }}=0.75(129 \mathrm{~mL}), T_{\mathrm{R}}=60{ }^{\circ} \mathrm{C}, p_{\mathrm{R}}=20 \mathrm{bar}$ $\left(\mathrm{CO} / \mathrm{H}_{2}=1 / 1\right), F=1000 \mathrm{rpm}, c_{[\mathrm{Rh}]}=0.05 \mathrm{~mol} \%(0.1$ $\mathrm{mmol}),[\mathrm{Rh}] /$ Biphephos $=1 / 5$.

The experimental equipment used in case 4 (transmissionbatch autoclave) consisted of a thermostated autoclave that 
had been built in-house (100 mL), with externally coupled magnetic stirring and a thermostated transmission cell that had also been built in-house. These were connected with a recycle loop using a hermetically sealed MicroPump gear pump. The liquid mixing time in the reactor was $30 \mathrm{~s}$ and the liquid mixing time for the entire system was $5 \mathrm{~min}$. The overall gas-liquid mass transfer was rapid, with $98 \%$ saturation occurring within 1 min. Gas purification columns were used for $\mathrm{Ar}, \mathrm{CO}$ and $\mathrm{H}_{2}$. Gas and liquid manifolds were present for introducing solvents and reactants. All materials in the experimental system that came into contact with the liquid phase were made from either SS316 (autoclave, transmission cell, pump head, all valves and transfer lines), Kalrez (seals), graphite (pump gear), Teflon (window spacers, stirrer bar, seal for fittings), or $\mathrm{CaF}_{2}$ (windows). The system was designed for a maximum operating pressure of 100 bar. The entire experimental system is documented in detail elsewhere. ${ }^{31}$

Reaction conditions: $m_{\text {total }}=50 \mathrm{~g}, w_{1 \text {-dodecene }}=0.25(74$ $\mathrm{mmol}), w_{\text {toluene }}=0.75(43 \mathrm{~mL}), T_{\mathrm{R}}=60{ }^{\circ} \mathrm{C}, p_{\mathrm{R}}=20 \mathrm{bar}(\mathrm{CO} /$ $\left.\mathrm{H}_{2}=1 / 1\right), F=1000 \mathrm{rpm}, c_{[\mathrm{Rh}]}=0.05 \mathrm{~mol} \%(0.04 \mathrm{mmol}$, $[\mathrm{Rh}] /$ Biphephos $=1 / 5$.

Continuous Miniplant Setup. The miniplant has already been discussed in a previous contribution. ${ }^{25}$

The ATR probe (React-IR 15, Thermo Fischer) can hold 69 bar and is connected to the sensor via an optical fiber. The tip of the probe is a diamond window where the total reflection is conducted and the spectroscopic data is collected. The ATR technique in combination with the optical fiber suffers from a low signal intensity. The diamond window has a selfadsorption of around $2000 \mathrm{~cm}^{-1}$, which limits the spectral data.

The transmission-IR (Vertex70, Bruker) needs a cuvette with a defined path length through the sample. This requires a steady stream of the sample solution from the reactor to the probe and back again. In a continuously operated miniplant, an installation is easier since the miniplant's internal streams can be used. The probe used is a self-designed high-pressure cell with $\mathrm{CaF}_{2}$ windows that have a self-absorbance below 1000 $\mathrm{cm}^{-1}$. Due to the higher intensity of the signals, the wavenumber range is much bigger.

Reaction conditions: $V_{\text {feed }}=104.5 \mathrm{~mL} \mathrm{~h}^{-1}, w_{\text {toluene }}=0.75$ $\left(78.4 \mathrm{~mL} \mathrm{~h}^{-1}\right), w_{1 \text {-dodecene }}=0.25\left(155 \mathrm{mmol} \mathrm{h}^{-1}\right), c_{[\mathrm{Rh}]}=0.05$ $\mathrm{mol} \%\left(8 \mathrm{mmol} \mathrm{h}^{-1}\right),[\mathrm{Rh}] /$ Biphephos $=1 / 5, \mathrm{~T}_{\mathrm{R}}=90^{\circ} \mathrm{C}, p=$ 20 bar, $\left(\mathrm{CO} / \mathrm{H}_{2}=1 / 1\right), F=500 \mathrm{rpm}, T_{\mathrm{OSN}}=30,8^{\circ} \mathrm{C}, V_{\mathrm{C} 1}^{\cdot}=$ $3 \mathrm{~L} \mathrm{~h}^{-1}, V_{\mathrm{C} 2}^{\cdot}=110 \mathrm{~L} \mathrm{~h}^{-1}, A_{\text {membrane }}=30 \mathrm{~cm}^{2}$.

\section{ASSOCIATED CONTENT}

\section{S Supporting Information}

The Supporting Information is available free of charge on the ACS Publications website at DOI: 10.1021/acscatal.8b05066.

Details of miniplant units, materials, analytical details, reaction conditions, DFT calculations and BTEM calculations (PDF)

\section{AUTHOR INFORMATION}

\section{Corresponding Author}

*A. J. Vorholt. E-mail: andreas-j.vorholt@cec.mpg.de. ORCID ${ }^{\circ}$

M. Stein: 0000-0001-7793-0052

A. J. Vorholt: 0000-0001-9302-2273

Notes

The authors declare no competing financial interest.

\section{ACKNOWLEDGMENTS}

We gratefully acknowledge the financial support of the German Science Foundation (Project SFB/TRR 63: "InPROMPT Integrated Chemical Processes in Multi-Phase Fluid Systems") for this work (Subproject B5). The Max Planck Society is acknowledged for funding. We also express our gratitude to Umicore AG \& Co. KG for supplying the catalyst precursors.

\section{REFERENCES}

(1) MacFarlane, D. R.; Zhang, X.; Kar, M. Measure and Control: Molecular Management Is a Key to the Sustainocene! Green Chem. 2016, 18, 5689-5692.

(2) Kubis, C.; Selent, D.; Sawall, M.; Ludwig, R.; Neymeyr, K.; Baumann, W.; Franke, R.; Börner, A. Exploring between the Extremes: Conversion-Dependent Kinetics of Phosphite-Modified Hydroformylation Catalysis. Chem. - Eur. J. 2012, 18, 8780-8794.

(3) Sawall, M.; Kubis, C.; Franke, R.; Hess, D.; Selent, D.; Börner, A.; Neymeyr, K. How to Apply the Complementarity and Coupling Theorems in MCR Methods: Practical Implementation and Application to the Rhodium-Catalyzed Hydroformylation. ACS Catal. 2014, 4, 2836-2843.

(4) Garland, M.; Li, C. A Review of BTEM Analysis for Catalytic Studies and a Recent Homogeneous Catalytic Example. Top. Catal. 2009, 52, 1334-1341.

(5) Liu, G.; Volken, R.; Garland, M. Unmodified RhodiumCatalyzed Hydroformylation of Alkenes Using Tetrarhodium Dodecacarbonyl. The Infrared Characterization of 15 Acyl Rhodium Tetracarbonyl Intermediates. Organometallics 1999, 18, 3429-3436.

(6) Widjaja, E.; Li, C.; Garland, M. Algebraic System Identification for a Homogeneous Catalyzed Reaction: Application to the RhodiumCatalyzed Hydroformylation of Alkenes Using in Situ FTIR Spectroscopy. J. Catal. 2004, 223, 278-289.

(7) Garland, M. Combining Operando Spectroscopy with Experimental Design, Signal Processing and Advanced Chemometrics: State-of-the-Art and a Glimpse of the Future. Catal. Today 2010, 155, 266-270.

(8) Marion, P.; Bernela, B.; Piccirilli, A.; Estrine, B.; Patouillard, N.; Guilbot, J.; Jérôme, F. Sustainable Chemistry: How to Produce Better and More from Less? Green Chem. 2017, 19, 4973-4989.

(9) Meißner, A.; Alberico, E.; Drexler, H.-J. J.; Baumann, W.; Heller, D. Rhodium Diphosphine Complexes: A Case Study for Catalyst Activation and Deactivation. Catal. Sci. Technol. 2014, 4, 3409-3425.

(10) Selent, D.; Heller, D. In-Situ Techniques for Homogeneous Catalysis. In Catalysis: From Principles to Applications; Beller, M., Renken, A., van Santen, R. A., Eds.; Wiley-VCH: Weinheim, 2012; pp 465-490.

(11) Chew, W.; Widjaja, E.; Garland, M. Band-Target Entropy Minimization (BTEM): An Advanced Method for Recovering Unknown Pure Component Spectra. Application to the FTIR Spectra of Unstable Organometallic Mixtures. Organometallics 2002, 21, 1982-1990.

(12) Li, C.; Widjaja, E.; Chew, W.; Garland, M. Rhodium Tetracarbonyl Hydride: The Elusive Metal Carbonyl Hydride. Angew. Chem. 2002, 114, 3939-3943.

(13) Haynes, A. The Use of High Pressure Infrared Spectroscopy to Study Catalytic Mechanisms. In Mechanisms in Homogeneous Catalysis; Heaton, B., Ed.; Wiley-VCH: Weinheim, Germany, 2005; pp 107150.

(14) Kamer, P. C. J.; van Rooy, A.; Schoemaker, G. C.; van Leeuwen, P. W. N. M. In Situ Mechanistic Studies in Rhodium Catalyzed Hydroformylation of Alkenes. Coord. Chem. Rev. 2004, 248, 2409-2424.

(15) van Leeuwen, P. W. N. M. Decomposition Pathways of Homogeneous Catalysts. Appl. Catal., A 2001, 212, 61-81.

(16) Börner, A.; Franke, R. Hydroformylation, 1st ed.; Wiley-VCH: Weinheim, Germany, 2016.

(17) Frey, G.; Dämbkes, G. 75 Jahre Oxo-Synthese: 75 Years of Oxo Synthesis; Klartext-Verlagsges: Essen, 2013. 
(18) van Leeuwen, P. W. N. M.; Claver, C. Rhodium Catalyzed Hydroformylation; Springer-Verlag: Heidelberg, 2000.

(19) Illner, M.; Müller, D.; Esche, E.; Pogrzeba, T.; Schmidt, M.; Schomäcker, R.; Wozny, G.; Repke, J. U. Hydroformylation in Microemulsions: Proof of Concept in a Miniplant. Ind. Eng. Chem. Res. 2016, 55, 8616-8626.

(20) Pogrzeba, T.; Schmidt, M.; Milojevic, N.; Urban, C.; Illner, M.; Repke, J. U.; Schomäcker, R. Understanding the Role of Nonionic Surfactants during Catalysis in Microemulsion Systems on the Example of Rhodium-Catalyzed Hydroformylation. Ind. Eng. Chem. Res. 2017, 56, 9934-9941.

(21) Dreimann, J. M.; Warmeling, H.; Weimann, J. N.; Künnemann, K.; Behr, A.; Vorholt, A. J. Selectivity of the Hydroformylation in a Miniplant: Catalyst, Solvent and Olefin Recycle in Two Loops. AIChE J. 2016, 62, 4377-4383.

(22) Dreimann, J. M.; Lutze, P.; Zagajewski, M.; Behr, A.; Górak, A.; Vorholt, A. J. Highly Integrated Reactor-Separator Systems for the Recycling of Homogeneous Catalysts. Chem. Eng. Process. 2016, 99, 124-131.

(23) Dreimann, J. M.; Hoffmann, F.; Skiborowski, M.; Behr, A.; Vorholt, A. J. Merging Thermomorphic Solvent Systems and Organic Solvent Nanofiltration for Hybrid Catalyst Recovery in a Hydroformylation Process. Ind. Eng. Chem. Res. 2017, 56, 1354-1359.

(24) Dreimann, J. M.; Vorholt, A. J.; Skiborowski, M.; Behr, A. Removal of Homogeneous Precious Metal Catalysts via Organic Solvent Nanofiltration. Chem. Eng. Trans. 2016, 47, 343-348.

(25) Dreimann, J. M.; Skiborowski, M.; Behr, A.; Vorholt, A. J. Recycling Homogeneous Catalysts Simply by Organic Solvent Nanofiltration: New Ways to Efficient Catalysis. ChemCatChem 2016, 8, 3330-3333.

(26) Behr, A.; Dreimann, J. M.; Zagajewski, M.; Vorholt, A. J. Hydroformylierung von 1-Dodecen Im Miniplantmaßstab Unter Verwendung von Thermomorphen Mehrkomponenten-Lösungsmittelsystemen. Chem. Ing. Tech. 2014, 86, 1535-1536.

(27) Cole-Hamilton, D. J.; Tooze, R. Catalyst Separation, Recorvery and Recycling; Cole-Hamilton, D. J., Tooze, R. P., Eds.; Catalysis by metal complexes; Springer-Verlag: Heidelberg, 2006; Vol. 30.

(28) van Leeuwen, P. W. N. M.; Chadwick, J. C. Homogeneous Catalysis; Wiley-VCH: Weinheim, 2011.

(29) Crabtree, R. H. Deactivation in Homogeneous Transition Metal Catalysis: Causes, Avoidance, and Cure. Chem. Rev. 2015, 115, 127-150.

(30) Scott, S. L. A Matter of Life(Time) and Death. ACS Catal. 2018, 8, 8597-8599.

(31) Gao, F.; Ng, K. P.; Li, C.; Krummel, K. I.; Allian, A. D.; Garland, M. A Versatile and Compact Experimental Apparatus for the On-Line Spectroscopic Study of Liquid-Phase Heterogeneous Catalytic Systems. J. Catal. 2006, 237, 49-57.

(32) Brunsch, Y.; Behr, A. Temperaturgesteuertes Katalysatorrecycling in Der Homogenen Übergangsmetallkatalyse: Minimierung Des Katalysatorleachings. Angew. Chem. 2013, 125, 1627-1631.

(33) Deglmann, P.; Schäfer, A.; Lennartz, C. Application of Quantum Calculations in the Chemical Industry-An Overview. Int. J. Quantum Chem. 2015, 115, 107-136.

(34) Sperger, T.; Sanhueza, I. A.; Kalvet, I.; Schoenebeck, F. Computational Studies of Synthetically Relevant Homogeneous Organometallic Catalysis Involving $\mathrm{Ni}, \mathrm{Pd}, \mathrm{Ir}$, and $\mathrm{Rh}$ : An Overview of Commonly Employed DFT Methods and Mechanistic Insights. Chem. Rev. 2015, 115, 9532-9586.

(35) Perro, A.; Lebourdon, G.; Henry, S.; Lecomte, S.; Servant, L.; Marre, S. Combining Microfluidics and FT-IR Spectroscopy: Towards Spatially Resolved Information on Chemical Processes. React. Chem. Eng. 2016, 1, 577-594.

(36) Widjaja, E.; Li, C.; Garland, M. Semi-Batch Homogeneous Catalytic in-Situ Spectroscopic Data. FTIR Spectral Reconstructions Using Band-Target Entropy Minimization (BTEM) without Spectral Preconditioning. Organometallics 2002, 21, 1991-1997.

(37) Jörke, A.; Seidel-Morgenstern, A.; Hamel, C. RhodiumBiPhePhos Catalyzed Hydroformylation Studied by Operando FTIR
Spectroscopy: Catalyst Activation and Rate Determining Step. J. Mol. Catal. A: Chem. 2017, 426, 10-14.

(38) Schmidt, S.; Baráth, E.; Larcher, C.; Rosendahl, T.; Hofmann, P. Rhodium-Catalyzed Hydroformylation of 1,3-Butadiene to Adipic Aldehyde: Revealing Selectivity and Rate-Determining Steps. Organometallics 2015, 34, 841-847.

(39) Dreimann, J. M.; Skiborowski, M.; Behr, A.; Vorholt, A. J. Recycling Homogeneous Catalysts Simply by Organic Solvent Nanofiltration: New Ways to Efficient Catalysis. ChemCatChem 2016, 8, 3330-3333.

(40) Sparta, M.; Børve, K. J.; Jensen, V. R. Activity of RhodiumCatalyzed Hydroformylation: Added Insight and Predictions from Theory. J. Am. Chem. Soc. 2007, 129, 8487-8499.

(41) van Leeuwen, P. W. N. M. Decomposition Pathways of Homogeneous Catalysts. Appl. Catal., A 2001, 212, 61-81.

(42) TURBOMOLE, V6.6; University of Karlsruhe and Forschungszentrum Karlsruhe GmbH, TURBOMOLE GmbH, 2014.

(43) Becke, A. D. Density-Functional Exchange-Energy Approximation with Correct Asymptotic Behavior. Phys. Rev. A: At., Mol., Opt. Phys. 1988, 38, 3098-3100.

(44) Perdew, J. P. Density-Functional Approximation for the Correlation Energy of the Inhomogeneous Electron Gas. Phys. Rev. B: Condens. Matter Mater. Phys. 1986, 33, 8822-8824.

(45) Weigend, F. Accurate Coulomb-Fitting Basis Sets for $\mathrm{H}$ to Rn. Phys. Chem. Chem. Phys. 2006, 8, 1057.

(46) Schäfer, A.; Huber, C.; Ahlrichs, R. Fully Optimized Contracted Gaussian Basis Sets of Triple Zeta Valence Quality for Atoms Li to Kr. J. Chem. Phys. 1994, 100, 5829-5835.

(47) Neugebauer, J.; Hess, B. A. Fundamental Vibrational Frequencies of Small Polyatomic Molecules from Density-Functional Calculations and Vibrational Perturbation Theory. J. Chem. Phys. 2003, 118, 7215.

(48) Kohls, E.; Stein, M. Vibrational Scaling Factors for Rh(I) Carbonyl Compounds. Contrib. - Maced. Acad. Sci. Arts, Sect. Nat., Math. Biotech. Sci. 2017, 38, 43-56. 